Systematic Review

\title{
Correlation of Picky Eating in Children's Growth: A Systematic Review
}

\section{Dona Muji Fitriana, Risna Nur Pradany and Apriana Rahmawati}

Faculty of Nursing, Universitas Airlangga, Surabaya, Indonesia

\begin{abstract}
Background: picky eating is a problem that is now common in children, characterized by not trying or limiting variations in food, especially vegetables and fruit. Picky eating has an important role in the development of children, both physically and emotionally, so that it becomes a concern for the parents.

Method: this systematic review aims to explain the correlation of picky eating on a child's growth using PRISMA approach from two database: Scopus and Proquest limited to the last 5 years; from 2015-2019 and obtained 15 articles that selected. Identification of articles using keywords ('picky eating' AND 'children' AND 'weight' or 'growth').

Result: according to the findings, it was found nine articles that mentioned picky eating had an effect on growth and six articles mentioned no effect. Limitation of this study is that there are other factors that influence picky eating in selected articles.

Conclusion: the most of the result from the studies show the behavior of picky eating in children can affect the growth of both body weight and height, and can also affect nutritional status, emotional status, physical activity and health status. Nurses can provide education about the effects of picky eating behavior on children in parents.
\end{abstract}

\section{ARTICLE HISTORY}

Received: Dec 26, 2019

Accepted: Dec 31, 2019

\section{KEYWORDS}

picky eating; children; growth; body weight

\section{CONTACT}

Dona Muji Fitriana $\triangle$ dona.muji.fitriana2018@fkp.unair.ac.id

$\risingdotseq$ Faculty of Nursing, Universitas Airlangga, Surabaya, Indonesia

Cite this as: Fitriana, D. M, Pradany, R, N and Rahmawati, A. (2019). Correlation of Picky Eating in Children's Growth: A Systematic Review. Jurnal Ners, 14(3si), 108-111. doi:http://dx.doi.org/10.20473/jn.v14i1.16991

\section{INTRODUCTION}

Parents often complain about their child's poor diet by picky eating. It's as a normal feature of development, children sometimes experience decreased appetite and decrease the rate of growth (Peterson et al., 2017) between 2 and 6 years of age (Cohen, Irby, Brown, Vander Schaaf, \& Skelton, 2016). Picky eating is the behavior of rejecting some unfamiliar foods or ingredients (Thompson, Cummins, Brown, \& Kyle, 2015). Further, it can result in long-term eating disorders in adolescence and early adulthood (Li et al., 2017). Especially on fruits and vegetables, and this requires important attention for parents.

Picky eating so far has not been understood the effect on body weight and height in children, where the problem can be at risk for nutritional status in children (Ghosh et al., 2018). In Southeast Asia there is a prevalence of overweight $4.2 \%$ from 19.9 million in Asia and $15.1 \%$ of 86.5 million in Asia experiencing stunting (United Nations Children's Fund, Organization, \& Bank, 2017). Growth in children who can be at risk for these problems is likely to be influenced by the eating behavior of children who are picky on food and more often consume unhealthy foods. Picky eating can also only be a concern for parents who are overweight, and have nothing to do with the problem of nutritional status in children (Berger, Hohman, Marini, Savage, \& Birch, 2016). It is necessary to discuss whether the behavior of picky eating in children is related to growth in children.

This study aims to explain the correlate of picky eating on a child's growth. Where children with picky eating have a greater risk of experiencing changes in body weight, either overweight, underweight or even obesity and changes in height are even at risk for stunting in childhood and adolescence. We hypothesize that children with picky eating will have a tendency to experience problems with their growth, both weight and height.

\section{MATERIALS AND METHODS}

\section{Search Strategy}

This systematic review was conducted and reported as per the guidelines from PRISMA (preferred reporting items for systematic reviews and metaanalyses) and we search in two database such as Scopus and ProQuest without study design and publication status restrictions. Studies were includes 
if reported result on children aged less than 18 years, publish in English, and limited to the last 5 years; from 2015 to 2019. Identification of articles using keywords picky eating, children, body weight and growth..

\section{Eligibility Criteria}

This systematic review was aimed to identify correlate of picky eating in children growth. We compile search results based on the results of screening titles and abstracts, removed duplicates to identify studies relevant to the objectives of this review abastracts were not included if studyes evaluated the following

\section{Data Included}

After screening the articles that have been found, the data is extracted based on the research design, number of samples used, language used and growth status in children. This type of analysis of this review requires a theme that is relevant to the purpose of the review. The theme groups used for the review and form of the unit of analysis are: study design, the age of population, sample size, and correlation of picky eating in children's growth.

\section{RESULTS}

\section{Study Characteristics}

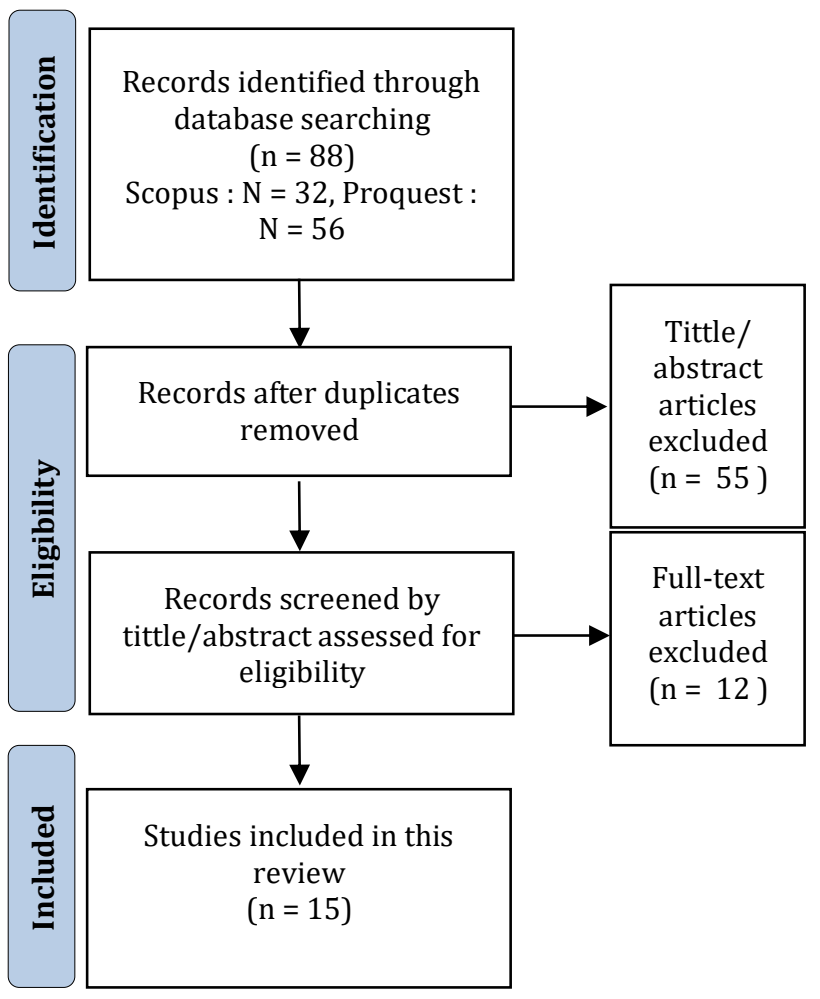

Figure 1. Result and Selection Procedure

Characteristics of the 15 selected articles are different. Of the studies included in analysis, 6 were cross-sectional, 5 were cohort study, and 3 randomized controll trial. Participant age ranged from 6 months to 17 years. Sample size varied from 153 to 5.700 children or mothers with their children.

\section{Correlate Picky Eating in Children Growth}

Of the 15 studies reviewed, 9 articles were found which mentioned a positive relationship between eating and growth and the 6 articles mentioned were not related. From 9 articles that positively related to the growth of children, 3 articles mentioned the correlation in increasing body weight and 6 articles mentioned the correlation between the occurrence of weight loss (Chao, 2018; Galloway, Watson, Pitama, Farrow, \& Llewellyn, 2018; Kwon, Shim, Kang, \& Paik, 2017; Viljakainen, Figueiredo, Rounge, \& Weiderpass, 2019; Volger et al., 2017). 6 articles that are negatively related, mention that the growth of children remains stable or normal but only related to diet or nutritional intake is even just an excessive concern by parents.

\section{DISCUSSION}

There is no clear correlation between picky food behavior and children's growth including 15 articles included in this study. Our findings indicate a wide range of the not same evidence, with results like no association between picky eating and weight status, to associations with either overweight or underweight. In addition, results of some individual studies were mixed, with many varying found depending on baseline BMI, gender, or the persistence of picky eating or when the kids are choose their meal. The definitions of picky eating varied significantly between studies, varying from parental referral to a subspecialist due to picky eating behaviors that interfered with daily routines.

These inconsistencies in the conceptualization and measurement of picky eating contribute in reported prevalence of picky eating and association with weight. Most of the studies in this review were cross-sectional. It is especially important to note that the odds ratios are not comparable in magnitude across study designs-for example, one study finding that overweight kids are five times as likely to be picky does not mean that picky kids are five times as likely to be over or under weight. Even in studies that found a relationship between picky eating and overweight like the article that made by (Taylor, Steer, Hays, \& Emmett, 2018)

Also, most studies did not clearly report possible effect modifiers e.g., types of foods offered to the child, parenting styles, oral nutritional supplementation, growth (Ghosh et al., 2018), nutritional status, development, physical activity, and health (Chao, 2018), sosioeconomy (Galloway et al., 2018) parent weight status) that could affect the relationship between eating behaviors and weight status. Other limitations that may affect the cumulative evidence in this systematic review include publication bias and the risk of selective reporting 
within studies. 15 studies in this review included children younger than 17 years old, 5 of these were cohort studies.

Our finding that severe or persistent picky eating is associated with increased odds of underweight suggests that these studies are describing different eating behaviors than many of the other studies like a recent article by Rohde et al. (Rohde et al., 2017). A study conducted in China said that small children with picky eating and heavy low-for-height behaviors have a less optimal diet and are at risk of significant food and nutritional deficiencies (Volger et al., 2017).

This information would indeed help clinicians in appropriately classifying pediatric patients and providing counsel for parents. The existing literature supports that food neophobia is common in children and does not put children at increased risk for being underweight (Viljakainen et al., 2019). However, given the variety of available definitions for picky eating, it is unclear if this finding would stand up for all. A more uniform definition of picky eating and a better understanding of the pathology of picky eating in various age groups are needed to clarify this literature. Further research also is warranted to examine how picky eating affects the timing of the BMI. In addition, more information is needed regarding the role of environment as a determinant of parents and children's food preferences and whether these environmental influences are responsible for maladaptive nutrition practices during childhood.

The sistematic review has several limitations. First, in sistematic review the study used has many study designs. Second, some studies found not only focus on the behavior of picky eating. Third, the systematic review of studies comes from various countries.

\section{CONCLUSION}

There is no resolution that can be used for the whole or general for all literature obtained. This is because there are very different conclusions about the prevalence of picky eating and this affects the status of nutrients, micro and macronutrients that enter the body, growth, development, height and weight, and future health. Parents play an important role in this matter from early childhood to adolescence, but old parents are used as respondents in this literature. The results of picky eating who have a habit of choosing foods that can lack substances actually needed by the body. There are a number of articles that discuss issues that cause the body not easy, but some articles will also discuss how to make more children than obese bodies.

\section{REFERENCES}

Antoniou, E. E., Sleddens, E. F. C., Thijs, C., Roefs, A., Kremers, S. P. J., Gubbels, J. S., \& Jansen, A. (2015). Picky eating and child weight status development: a longitudinal study. Journal of Human Nutrition and Dietetics, 29(3), 298-307. https://doi.org/10.1111/jhn.12322
Berger, P. K., Hohman, E. E., Marini, M. E., Savage, J. S., \& Birch, L. L. (2016). Girls' picky eating in childhood is associated with normal weight status from ages 5 to $15 \mathrm{y} 1,2$. American Journal of Clinical Nutrition, 104(6), 1577-1582. https://doi.org/10.3945/ajcn.116.142430

Chao, H.-C. (2018). Association of Picky Eating with Growth, Nutritional Status, Development, Physical Activity, and Health in Preschool Children. Frontiers in Pediatrics, 6(February), 1-9. https://doi.org/10.3389/fped.2018.00022

Cohen, G. M., Irby, M. B., Brown, C. L., Vander Schaaf, E. B., \& Skelton, J. A. (2016). Association of Picky Eating and Food Neophobia with Weight: A Systematic Review. Childhood Obesity, 12(4), 247262. https://doi.org/10.1089/chi.2015.0189

Galloway, A. T., Watson, P., Pitama, S., Farrow, C. V, \& Llewellyn, C. H. (2018). Socioeconomic Position and Picky Eating Behavior Predict Disparate Weight Trajectories in Infancy. Frontiers in Endocrinology, 9(September), 1-9. https://doi.org/10.3389/fendo.2018.00528

Ghosh, A. K., Kishore, B., Shaikh, I., Satyavrat, V., Kumar, A., Shah, T., ... Huynh, D. T. T. (2018). Continuation of Oral Nutritional Supplementation Supports Continued Growth in Nutritionally Atrisk Children with Picky Eating Behaviour: A Postintervention, Observational Follow-up Study. https://doi.org/10.1177/0300060518766982

Kwon, K. M., Shim, J. E., Kang, M., \& Paik, H. (2017). Association between Picky Eating Behaviors and Nutritional Status in Early Childhood: Performance of a Picky Eating Behavior Questionnaire. https://doi.org/10.3390/nu9050463

Li, Z., Horst, K. Van Der, Edelson-fries, L. R., Yu, K., You, L., Zhang, Y., ... Wang, J. (2017). Perceptions of food intake and weight status among parents of picky eating infants and toddlers in China: A crosssectional study. Appetite, 108, 456-463. https://doi.org/10.1016/j.appet.2016.11.009

Peterson, K. E., Ball, S. C., Brown, C. L., Lumeng, J. C., Perrin, E. M., Horodynski, M. A., ... Contreras, D. (2017). Association of Picky Eating With Weight Status and Dietary Quality Among Low-Income Preschoolers. Academic Pediatrics, 18(3), 334341. https://doi.org/10.1016/j.acap.2017.08.014

Rohde, J. F., Trærup, M., Stougaard, M., Olsen, N. J., Mortensen, E. L., Heitmann, B. L., \& Händel, M. N. (2017). Relationship between pickiness and subsequent development in body mass index and diet intake in obesity prone normal weight preschool children. Plos One, 12(3), e0172772. https://doi.org/10.1371/journal.pone.0172772

Sandvik, P., Ek, A., Somaraki, M., Hammar, U., Eli, K., \& Nowicka, P. (2018). Picky eating in Swedish preschoolers of different weight status: application of two new screening cut-offs. International Journal of Behavioral Nutrition \& Physical Activity, 15(1), N.PAG-N.PAG. https://doi.org/http://dx.doi.org/10.1186/s129 66-018-0706-0 
Taylor, C. M., Steer, C. D., Hays, N. P., \& Emmett, P. M. (2018). Growth and body composition in children who are picky eaters: a longitudinal view. European Journal of Clinical Nutrition, 1-10. https://doi.org/10.1038/s41430-018-0250-7

Thompson, C., Cummins, S., Brown, T., \& Kyle, R. (2015). What does it mean to be a "picky eater"? A qualitative study of food related identities and practices. Appetite, 84, 235-239. https://doi.org/10.1016/j.appet.2014.09.028

United Nations Children's Fund, Organization, W. H., \& Bank, T. W. (2017). Levels \& trends in child malnutrition. https://doi.org/10.1016/S02666138(96)90067-4

Viljakainen, H. T., Figueiredo, R. A. O., Rounge, T. B., \& Weiderpass, E. (2019). Picky eating - A risk factor for underweight in Finnish preadolescents. Appetite, 133(March 2018), 107-114. https://doi.org/10.1016/j.appet.2018.10.025

Volger, S., Sheng, X., Tong, L. M., Zhao, D., Fan, T.,
Zhang, F., ... Yao, M. (2017). Nutrient Intake and Dietary Patterns in Children 2 . 5-5 years of Age with Picky Eating Behaviours and Low Weight-forheight. Asia Pacific Jurnal Clinical Nutrition, 26(August 2015), 104-109. https://doi.org/10.6133/apjcn.102015.02

Xue, Y., Lee, E., Ning, K., Zheng, Y., Ma, D., Gao, H., ... Zhang, Y. (2015). Prevalence of picky eating behaviour in Chinese school-age children and associations with anthropometric parameters and intelligence quotient. A cross-sectional study. Appetite, 91, 248-255. https://doi.org/10.1016/j.appet.2015.04.065

Xue, Y., Ma, D., Szeto, I. M. Y., Cai, L., Wang, P., Zhao, A., ... Zhang, Y. (2015). Growth and Development in Chinese Pre-Schoolers with Picky Eating Behaviour: A Cross-Sectional Study. Plos One, 10(4), e0123664. https://doi.org/10.1371/journal.pone.0123664 